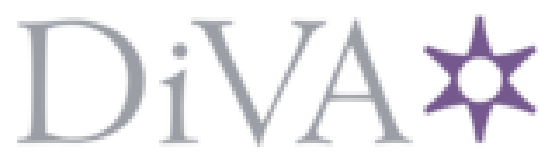

http://www.diva-portal.org

This is the published version of a paper published in Applied Physics Letters.

Citation for the original published paper (version of record):

Zhang, D., Must, I., Netzer, N L., Xu, X., Solomon, P. et al. (2016)

Direct assessment of solidâ\#\#liquid interface noise in ion sensing using a differential method.

Applied Physics Letters, 108(15)

http://dx.doi.org/10.1063/1.4946857

Access to the published version may require subscription.

N.B. When citing this work, cite the original published paper.

Permanent link to this version:

http://urn.kb.se/resolve?urn=urn:nbn:se:uu:diva-283484 


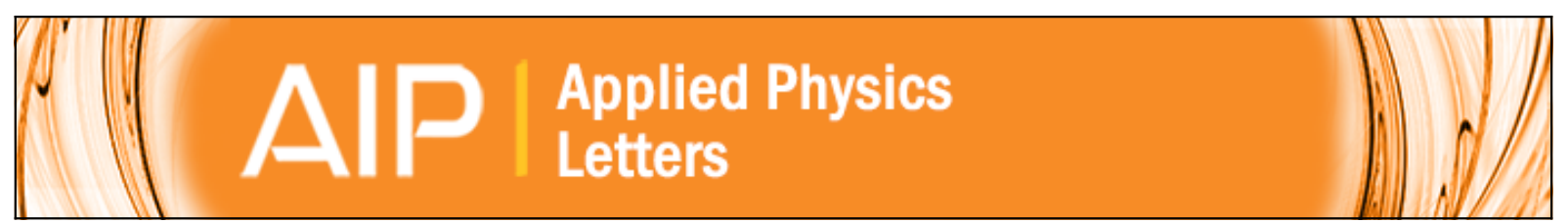

\section{Direct assessment of solid-liquid interface noise in ion sensing using a differential method}

Da Zhang, Indrek Must, Nathan L. Netzer, Xingxing Xu, Paul Solomon, Shi-Li Zhang, and Zhen Zhang

Citation: Applied Physics Letters 108, 151603 (2016); doi: 10.1063/1.4946857

View online: http://dx.doi.org/10.1063/1.4946857

View Table of Contents: http://scitation.aip.org/content/aip/journal/apl/108/15?ver=pdfcov

Published by the AIP Publishing

\section{Articles you may be interested in}

A high pressure $x$-ray photoelectron spectroscopy experimental method for characterization of solid-liquid interfaces demonstrated with a Li-ion battery system

Rev. Sci. Instrum. 86, 044101 (2015); 10.1063/1.4916209

Ab initio study of EMIM- BF 4 crystal interaction with a Li (100) surface as a model for ionic liquid/Li interfaces in Li-ion batteries

J. Chem. Phys. 131, 244705 (2009); 10.1063/1.3273087

Frontside illuminated $\mathrm{TiO} 2$ nanotube dye-sensitized solar cells using multifunctional microchannel array electrodes

Appl. Phys. Lett. 95, 233505 (2009); 10.1063/1.3272109

Improved quasi-solid dye-sensitized solar cells by composite ionic liquid electrolyte including layered $\alpha$ zirconium phosphate

Appl. Phys. Lett. 89, 194104 (2006); 10.1063/1.2387967

Pumping of liquids with traveling-wave electroosmosis

J. Appl. Phys. 97, 084906 (2005); 10.1063/1.1873034

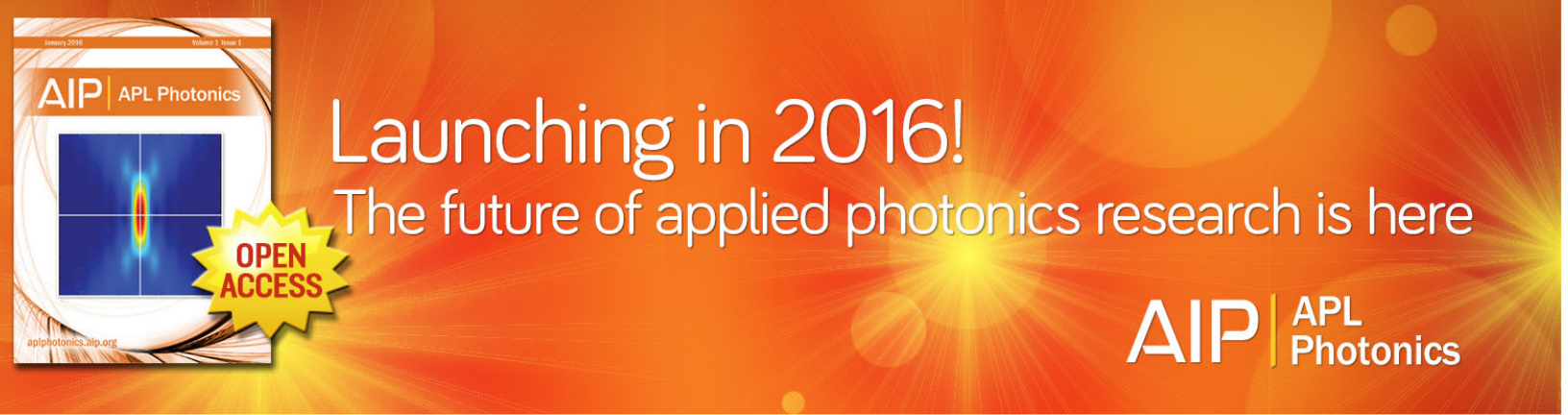




\title{
Direct assessment of solid-liquid interface noise in ion sensing using a differential method
}

\author{
Da Zhang, Indrek Must, Nathan L. Netzer, Xingxing Xu, Paul Solomon, ${ }^{\text {a) }}$ Shi-Li Zhang, \\ and Zhen Zhang ${ }^{\text {b) }}$ \\ Solid-State Electronics, The Ångström Laboratory, Uppsala University, SE-751 21 Uppsala, Sweden
}

(Received 23 February 2016; accepted 29 March 2016; published online 12 April 2016)

\begin{abstract}
This letter presents a microelectrode cell dedicated to direct assessment of the solid-liquid interface noise without recourse to a reference electrode. In the present design, two identical TiN electrodes of various sizes are used for differential measurements in KCl-based electrolytes. Measured noise of the TiN|electrolyte system is found to be of thermal nature. Scaling inversely with electrode area, the noise is concluded to mainly arise from the solid-liquid interface. This noise is comparable to or larger than that of the state-of-the-art MOSFETs. Therefore, its influence cannot be overlooked for the design of future ion sensors. Published by AIP Publishing.

[http://dx.doi.org/10.1063/1.4946857]
\end{abstract}

The state-of-the-art of ion sensitive field-effect transistor (ISFET) technology ${ }^{1}$ can be well represented by its successful applications in semiconductor genome sequencing ${ }^{2}$ and quantitative polymerase chain reaction (qPCR). ${ }^{3}$ An ISFET system comprises three elements: the FET itself, sampling electrolyte, and electrical double layer (EDL) at the solidliquid interface. ${ }^{4}$ Sensing by an ISFET is achieved via monitoring the change in EDL potential, $\Delta \varphi_{\mathrm{DL}}$, caused by surface binding of specific ions available in the electrolyte to the sensing electrode (mostly an oxide layer). $\Delta \varphi_{\mathrm{DL}}$ in its turn induces a change in source-drain current of the FET. This field effect will, by definition, also transfer the noise generated in the electrolyte as well as in the EDL to the output end along with the signal. Such noise is intrinsic per se for an ISFET system, precisely as the noise due to channel conductance fluctuation in the FET itself. ${ }^{5}$ Any attempt for signal amplification such as that with the integration of a local lownoise bipolar transistor next to an ISFET $^{6}$ will also inevitably amplify the various intrinsic noise components.

The noise of the ISFET system has received extensive treatments both theoretically ${ }^{7-9}$ and experimentally. ${ }^{10-14}$ While noise from the FET can be understood from the well-established theory and practice for a corresponding MOSFET, ${ }^{5}$ noise generated in the electrolyte as well as in the EDL in the ISFET context is much less characterized. In some simulation studies, ${ }^{8,9}$ the former (i.e., liquid noise) is considered the main contributor in the form of thermal noise due to the Brownian motion of ions in the electrolyte, and the latter (i.e., EDL noise) is often assumed negligible. In view of great similarities between random ion adsorption/desorption in the EDL leading to fluctuations in $\Delta \varphi_{\mathrm{DL}}$ and random charge trapping/de-trapping at the oxide $\mid \mathrm{Si}$ interface leading to fluctuations in channel conductance of the FET, ${ }^{5}$ it is of importance scientifically and technologically to quantify the EDL noise. We have, therefore,

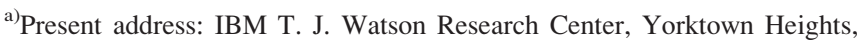
New York 10598, USA.

b) Author to whom correspondence should be addressed. Electronic mail: zhen.zhang@angstrom.uu.se.
}

fabricated a dedicated microelectrode cell to specifically investigate the noise components associated with the liquid. As shown in Fig. 1, a TiN microelectrode is used in this study. Our choice of TiN exploits the inevitable formation of a native $\mathrm{TiO}_{\mathrm{x}}$ layer that has an ideal Nernstian response with $59 \mathrm{mV} / p \mathrm{H}$ at room temperature. ${ }^{15}$ Two identical wings are designed in the microelectrode cell in order to facilitate a direct assessment of the voltage noise via differential measurements. The measured voltage noise clearly shows a 1/area dependence, which indicates the dominance of the EDL noise in our system. This EDL noise is further found to be larger than the FET noise of the state-of-the-art MOSFET technologies. ${ }^{16-18}$

The microelectrode cell schematically shown in Fig. 1 was fabricated using standard Si technology. First, a 100-nm thick TiN layer was sputter-deposited on a Si wafer covered with a 500-nm thick thermally grown insulating $\mathrm{SiO}_{2}$ layer. This was followed by photolithography in combination with reactive ion etching to define the microelectrode. Then, circular openings in SU8 2002 resist were patterned using photolithography to expose the TiN surface to the sampling electrolyte. The diameter of the openings varied from

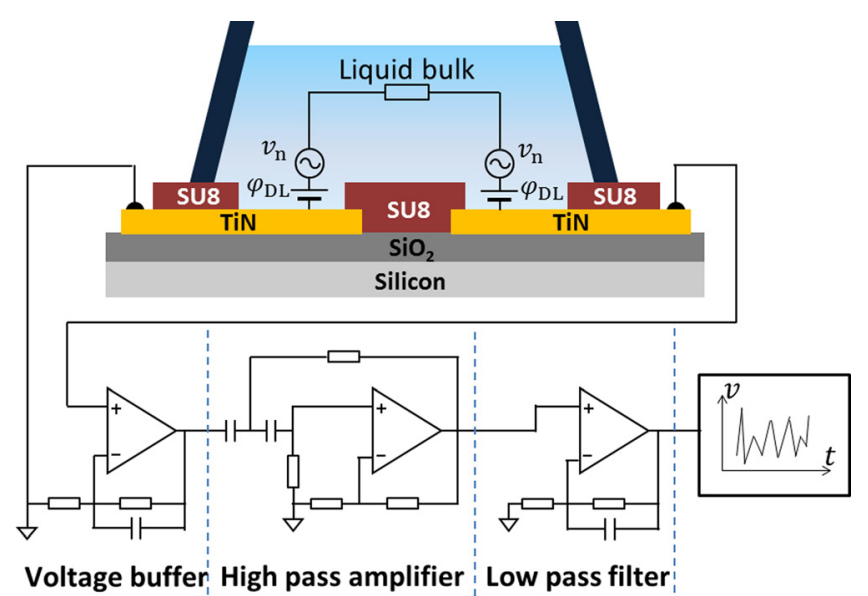

FIG. 1. Schematic cross section of our electrode cell and the potentiometric noise measurement setup for noise characterization in liquid. 
$100 \mu \mathrm{m}$ to $1000 \mu \mathrm{m}$, with the SU8 resist to passivate the rest of the cell. During noise measurement, the TiN electrodes were electrically bridged by the electrolyte. The SU8 openings, inspected by scanning electron microscopy, were confined within the patterned TiN area, thereby ensuring exposure of only the TiN surface to the electrolyte. The surface of the TiN electrodes was free from SU8 contamination within the detection limit of Raman spectroscopy.

The differential measurement setup is also schematically shown in Fig. 1. The measurement loop comprises two TiN electrodes and a $\mathrm{KCl}$ (Merck) aqueous solution as the sampling electrolyte. The $\mathrm{KCl}$ solution was chosen because it is a common standard ionic solution. We used various $\mathrm{KCl}$ concentrations from $1 \mathrm{mM}$ to $1 \mathrm{M}$ at two $p \mathrm{H}$ values 6 and 2. For a given $p \mathrm{H}$ value, equal amount of DC EDL potentials $\varphi_{\mathrm{DL}}$ would build up at the two identical $\mathrm{TiN}_{\mathrm{N}}\left|\mathrm{TiO}_{\mathrm{x}}\right| \mathrm{KCl}$ interfaces. As they were face-to-face in the measurement loop, their DC components $\left(\varphi_{\mathrm{DL}}\right)$ would cancel out with each other. In contrast, two identical AC voltage noise sources, $v_{\mathrm{n}}$, would be in series and independent of each other, as indicated in the schematics. The total measured noise power would, then, be a summation of the contributions from the bulk electrolyte and the two EDLs. To measure the voltage noise, a custom preamplifier with a $0.1 \mathrm{~Hz}-1 \mathrm{kHz}$ bandpass filter and a gain of $10 \mathrm{k}$ were constructed using OPA140 operational amplifiers, and the signal was digitized using a Keysight U2351a multifunction data acquisition device. The electrical potential variation between the two electrodes was sampled at $10 \mathrm{kHz}$, and 4 million data points were used to generate a voltage noise power spectral density (PSD) spectrum, $S_{\mathrm{V}}^{\text {pot }}$. The noise PSD was divided by 2 so as to normalize it to a single electrode.

In addition, the sample was characterized by electrochemical impedance spectroscopy (EIS) using a Bio-Logic VSP300 potentiostat. The EIS spectrum was measured at $10 \mathrm{mV}$ root-mean-square AC from $100 \mathrm{mHz}$ to $1 \mathrm{MHz}$. The measurement data were averaged over 30 cycles for each frequency point. The Johnson-Nyquist (J-N) noise was calculated from the real part of the impedance using $S_{\mathrm{V}}^{\mathrm{imp}}=4 k T \operatorname{Re}[Z(f)]$, where $k$ is the Boltzmann constant, $T$ is the temperature in Kelvin, $Z(f)$ is impedance, and $f$ is frequency, and it was also divided by 2 to normalize it to a single electrode.

We first analyzed the voltage noise on the TiN electrodes in $1 \mathrm{M} \mathrm{KCl}$. $S_{\mathrm{V}}^{\mathrm{pot}}$ and $S_{\mathrm{V}}^{\mathrm{imp}}$ are shown in Fig. 2(a) as a function of $f$ for different TiN electrode areas. For the largest area in our design with a diameter of $1000 \mu \mathrm{m}$, the lowest values of $S_{\mathrm{V}}^{\text {pot }}$ are equal to the floor noise, $S_{\mathrm{V}}^{\text {floor }}$ of the amplifier, for $f>50 \mathrm{~Hz}$. By taking $S_{\mathrm{V}}^{\text {floor }}$ into account, an excellent agreement between $S_{\mathrm{V}}^{\text {pot }}$ and $S_{\mathrm{V}}^{\text {imp }}$ in the entire measurement frequency range for all electrode areas is found. This verifies the absence of any major noise component other than J-N noise. ${ }^{19}$

In $\log$ - $\log$ scale, $S_{\mathrm{V}}^{\mathrm{imp}}$ is observed to be linearly dependent on $f$ with a slope $-\gamma$ for all TiN electrode areas displayed. The low-frequency behavior of an EDL can be described using a phenomenological equivalent circuit component referred to as the constant phase element (CPE), ${ }^{20}$ with $Z(f)=1 / Q(i f)^{\gamma}$, where $i$ is the imaginary unit and $Q$ is a CPE parameter. The frequency dependency of $S_{\mathrm{V}}^{\text {imp }}$ on $f$ follows then a $1 / f^{\gamma}$ relation, based on the relation $S_{\mathrm{v}}=4 k T \operatorname{Re}[Z(f)]$. Here, we obtain $\gamma=0.77$ by linear fitting in Fig. 2(a).
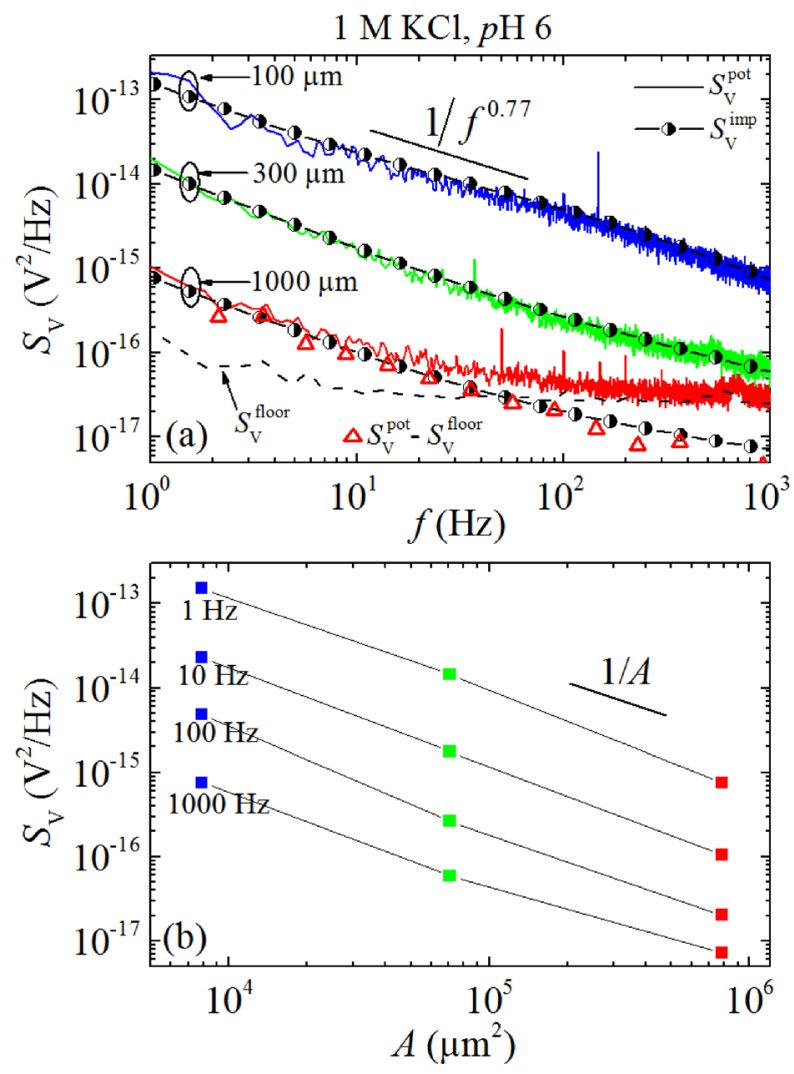

FIG. 2. (a) $S_{\mathrm{V}}^{\text {pot }}$ and $S_{\mathrm{V}}^{\text {imp }}$ vs. $f$ for several electrode areas. (b) $S_{\mathrm{v}}$ vs. $A$ at different frequencies. The data were extracted from $S_{\mathrm{V}}^{\text {imp }}$.

The dependency of $S_{\mathrm{V}}$ on electrode area, $A$, at several frequencies is shown in Fig. 2(b). The measured noise $S_{\mathrm{V}}$ scales inversely with $A$ and has a unity slope in the log-log scale. In contrast, the bulk resistance of the electrolyte, $R_{\mathrm{b}}$, can be approximated by its spreading resistance as $R_{\mathrm{b}} \propto K / \sqrt{A}{ }^{8}$, with $K$ as the resistivity of the liquid bulk. The thermal noise generated by the bulk liquid should then scale with $1 / \sqrt{A}$. For our samples, the EDL impedance is much larger than $R_{\mathrm{b}}$ for all but the largest area at the highest frequency. This is supported by the results in Fig. 2(b) that show a $1 / A$ dependency over most of the range.

Finally, the area-normalized $S_{\mathrm{V}}$ of the $300 \mu \mathrm{m}$ diameter TiN electrode is compared in Fig. 3 with the area-normalized

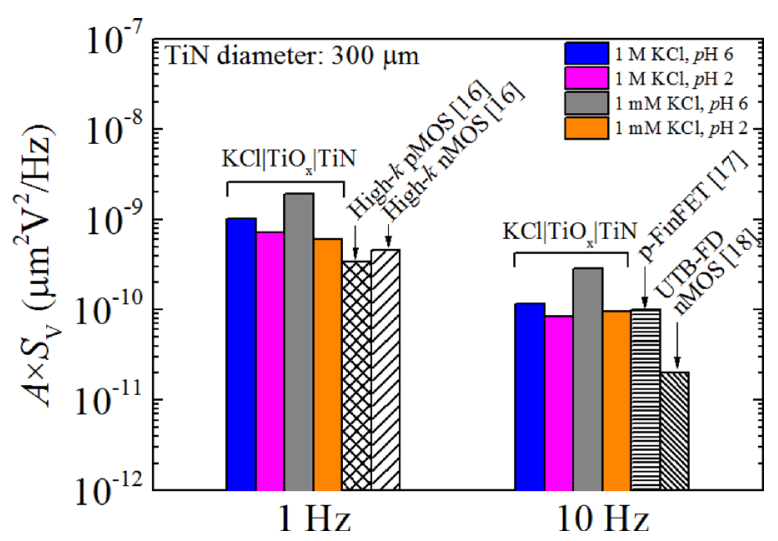

FIG. 3. Comparison of area-normalized solid-liquid noise with inputreferred noise of state-of-the-art MOSFETs at 1 and $10 \mathrm{~Hz}$. 
input-referred noise of several state-of-the-art MOSFETs. ${ }^{16-18}$ The comparison is made at $1 \mathrm{~Hz}$ and $10 \mathrm{~Hz}$, and includes different combinations of $\mathrm{KCl}$ concentration and $p \mathrm{H}$ value for the $\mathrm{TiN}$ electrode. It is apparent that the EDL noise is comparable or even higher than that of the reported advanced MOSFETs and cannot be neglected. Additionally, when the $\mathrm{KCl}$ concentration was reduced from $1 \mathrm{M}$ to $1 \mathrm{mM}$ at $p \mathrm{H}=6$ with a negligible proton concentration, the observed change in $S_{\mathrm{V}}$ was too small to associate to an increase in $R_{\mathrm{b}}$ by about three orders of magnitude. This further confirms the minor role of the noise generated in the electrolyte bulk.

In contrast to the assumptions of others, ${ }^{8,9}$ the real part of the measured sample impedance is much larger than the liquid impedance. We speculate that this is due to a rate limiting interfacial interaction or diffusion process at the liquid-solid boundary. It is striking and has also been documented in the literature ${ }^{19}$ that the voltage noise too closely follows the $\mathrm{J}-\mathrm{N}$ formula. We believe that this is due to the fact that our system, measured under conditions of negligible current flow, is close to thermal equilibrium. Since the noise frequency dispersion is close to $1 / f$, we may infer that even $1 / f$ noise obeys the $\mathrm{J}-\mathrm{N}$ relation for systems close to thermal equilibrium. Another ubiquitous feature of these systems is the existence of the CPE with a phase between $-\pi / 4$ and $-\pi / 2$. No physical electrical network can give this relationship, but it could be approximated by a non-uniform distributed network. Elucidation of the physics behind the CPE is a subject of further study.

We have demonstrated a methodology for direct assessment of the solid-liquid interface noise. It builds on a cell design with two identical face-to-face electrodes that can facilitate differential measurements. The demonstration uses TiN electrodes and KCl-based electrolytes. The directly measured voltage noise is found to agree excellently with the thermal noise obtained using impedance measurement, which indicates the thermal nature of the measured noise. The observed 1/area dependency of the measured noise reveals that the noise generated in the electrolyte bulk is negligible in comparison with that originates from the solidliquid interface even for a high-conductivity electrolyte with $1 \mathrm{M} \mathrm{KCl}$. The measured solid-liquid interface noise is comparable or higher than the input-referred noise of the stateof-the-art MOSFETs. Therefore, the solid-liquid interface noise should be taken into consideration for the design of future ISFETs.
The authors are grateful for the financial support from the Swedish Strategic Research Foundation (SSF ICA 120047), the Swedish Research Council (2014-5588, 20145591, and 2014-6300), Göran Gustafssons Foundation (GG 1459B), Carl Tryggers Foundation (CTS14-527), and China Scholarship Council via a scholarship (Da Zhang).

${ }^{1}$ P. Bergveld, IEEE Trans. Biomed. Eng. 17, 70 (1970).

${ }^{2}$ J. M. Rothberg, W. Hinz, T. M. Rearick, J. Schultz, W. Mileski, M. Davey, J. H. Leamon, K. Johnson, M. J. Milgrew, M. Edwards, J. Hoon, J. F. Simons, D. Marran, J. W. Myers, J. F. Davidson, A. Branting, J. R. Nobile, B. P. Puc, D. Light, T. A. Clark, M. Huber, J. T. Branciforte, I. B. Stoner, S. E. Cawley, M. Lyons, Y. Fu, N. Homer, M. Sedova, X. Miao, B. Reed, J. Sabina, E. Feierstein, M. Schorn, M. Alanjary, E. Dimalanta, D. Dressman, R. Kasinskas, T. Sokolsky, J. A. Fidanza, E. Namsaraev, K. J. McKernan, A. Williams, G. T. Roth, and J. Bustillo, Nature 475, 348 (2011).

${ }^{3}$ C. Toumazou, L. M. Shepherd, S. C. Reed, G. I. Chen, A. Patel, D. M. Garner, C.-J. A. Wang, C.-P. Ou, K. Amin-Desai, P. Athanasiou, H. Bai, I. M. Q. Brizido, B. Caldwell, D. Coomber-Alford, P. Georgiou, K. S. Jordan, J. C. Joyce, M. La Mura, D. Morley, S. Sathyavruthan, S. Temelso, R. E. Thomas, and L. Zhang, Nat. Methods 10, 641 (2013).

${ }^{4}$ P. Bergveld, Sens. Actuators, B 88, 1 (2003).

${ }^{5}$ K. K. Hung, P. K. Ko, C. Hu, and Y. C. Cheng, IEEE Trans. Electron Devices 37, 654 (1990).

${ }^{6}$ D. Zhang, X. Gao, S. Chen, H. Norström, U. Smith, P. Solomon, S.-L. Zhang, and Z. Zhang, Appl. Phys. Lett. 105, 082102 (2014).

${ }^{7}$ A. Hassibi, R. Navid, R. W. Dutton, and T. H. Lee, J. Appl. Phys. 96, 1074 (2004).

${ }^{8}$ M. J. Deen, M. W. Shinwari, J. C. Ranuarez, and D. Landheer, J. Appl. Phys. 100, 74703 (2006).

${ }^{9}$ J. Go, P. R. Nair, and M. A. Alam, J. Appl. Phys. 112, 34516 (2012).

${ }^{10}$ C. G. Jakobson and Y. Nemirovsky, IEEE Trans. Electron Devices 46, 259 (1999).

${ }^{11}$ N. K. Rajan, D. A. Routenberg, and M. A. Reed, Appl. Phys. Lett. 98, 264107 (2011).

${ }^{12}$ K. Bedner, V. A. Guzenko, A. Tarasov, M. Wipf, R. L. Stoop, S. Rigante, J. Brunner, W. Fu, C. David, M. Calame, J. Gobrecht, and C. Schönenberger, Sens. Actuators, B 191, 270 (2014).

${ }^{13}$ N. K. Rajan, K. Brower, X. Duan, and M. A. Reed, Appl. Phys. Lett. 104, 084106 (2014).

${ }^{14}$ N. K. Rajan, D. A. Routenberg, J. Chen, and M. A. Reed, IEEE Electron Device Lett. 31, 615 (2010).

${ }^{15}$ Y. Wang, H. Yuan, X. Lu, Z. Zhou, and D. Xiao, Electroanalysis 18, 1493 (2006).

${ }^{16}$ H. Achour, R. Talmat, B. Cretu, J. M. Routoure, A. Benfdila, R. Carin, N. Collaert, E. Simoen, A. Mercha, and C. Claey, Solid-State. Electron. 90, 160 (2013).

${ }^{17}$ E. Simoen, A. Veloso, Y. Higuchi, N. Horiguchi, and C. Claeys, IEEE Trans. Electron Devices 60, 3849 (2013).

${ }^{18}$ C. G. Theodorou, E. G. Ioannidis, F. Andrieu, T. Poiroux, O. Faynot, C. A. Dimitriadis, G. Ghibaudo, and S. Member, IEEE Trans. Electron Devices 61, 1161 (2014).

${ }^{19}$ R. C. Gesteland, J. Y. Lettvin, B. Howland, B. Howland, and W. H. Pitts, Proc. IRE 47, 1856 (1959).

${ }^{20}$ G. Láng and K. E. Heusler, J. Electroanal. Chem. 457, 257 (1998). 